\title{
Aspectos da composição química e aceitação sensorial da aguardente de cana-de-açúcar envelhecida em tonéis de diferentes madeiras
}

\author{
Aspects of the chemical composition and sensorial acceptance \\ of sugar cane spirit aged in casks of different types of woods
}

\author{
André Ricardo ALCARDE ${ }^{1 \star}$, Paula Araújo de SOUZA ${ }^{1}$, André Eduardo de Souza BELLUCO ${ }^{1}$
}

\begin{abstract}
Resumo
Este trabalho determinou aspectos da composição química e aceitação sensorial da aguardente de cana-de-açúcar envelhecida por 3 anos em tonéis de diferentes madeiras (amendoim, araruva, cabreúva, carvalho, cerejeira, grápia, ipê-roxo, jequitibá e pereira). O destilado alcoólico simples que originou a aguardente foi produzido na Destilaria Piloto da ESALQ/USP. Após envelhecimento, as aguardentes foram avaliadas quanto ao grau alcoólico, acidez volátil, furfural, aldeídos, ésteres, álcoois superiores, álcool metílico, cobre, compostos fenólicos totais, cor e aceitação sensorial. Independentemente da madeira com que o tonel foi construído, a aguardente envelhecida apresentou coloração mais escura e maior concentração de acidez volátil, de furfural, de ésteres, de álcoois superiores, de congêneres e de compostos fenólicos totais que o destilado alcoólico simples. Por outro lado, a aguardente envelhecida apresentou menor concentração de aldeídos, de metanol e de cobre que o destilado alcoólico simples. A análise estatística geral, considerando a composição físico-química global das aguardentes envelhecidas nos tonéis das diferentes madeiras indicou similaridades entre as aguardentes envelhecidas nos tonéis de amendoim, araruva e jequitibá; entre as aguardentes envelhecidas nos tonéis de cabreúva e pereira; e entre as aguardentes envelhecidas nos tonéis de carvalho, cerejeira, grápia e ipê-roxo. A aguardente envelhecida nos tonéis das diferentes madeiras manteve-se dentro de todos os padrões de qualidade estabelecidos pela legislação nacional em vigor. A aguardente envelhecida na madeira carvalho foi a que apresentou a melhor aceitação sensorial. Dentre as madeiras nacionais, ipê-roxo, amendoim, cabreúva, cerejeira e pereira foram aquelas que propiciaram as melhores qualidades sensoriais à aguardente.
\end{abstract}

Palavras-chave: composição; aguardente; envelhecimento; madeiras.

\begin{abstract}
This study evaluated some aspects of the chemical composition and sensorial acceptance of sugar cane spirit aged for 3 years in casks of different types of wood (peanut wood, araruva or striped wood, red cabreuva, oak, cherrywood, Brazilian gold wood, purple tabebuia, cariniana legalis, and pear tree). The simple alcoholic distillate which originated the sugar cane spirit was produced at the Distillery of ESALQ/USP. After aging, the sugar cane spirits were analyzed in terms of ethanol concentrations o, volatile acidity, furfural, aldehydes, esters, higher alcohols, methanol, copper, total phenolic compounds, color, and sensorial acceptance. Regardless the type of wood the casks were made of, the aged sugar cane spirits became darker and presented higher concentrations of volatile acidity, furfural, esters, higher alcohols, congeners, and total phenolic compounds than the simple alcoholic distillate. On the other hand, the aged sugar cane spirits presented lower concentrations of aldehydes, methanol, and copper than the simple alcoholic distillate. The statistical analysis, considering the global physicochemical composition of the sugar cane spirits aged in the casks made of different types of wood, showed similarities among the sugar cane spirits aged in the casks of peanut wood, araruva or striped wood, and cariniana legalis. It also indicates similarities among the sugar cane spirits aged in the casks of red cabreuva and pear tree and among the sugar cane spirits aged in the casks of oak, cherrywood, Brazilian gold wood, and purple tabebuia. The sugar cane spirits aged in the casks of the different types of wood were in accordance with the composition and quality standards established by the Brazilian laws. The sugar cane spirit aged in oak presented the best sensorial acceptance. Among the Brazilian woods, purple tabebuia, peanut wood, red cabreuva, cherrywood and pear tree were those that produced sugar cane spirits with better sensorial qualities.
\end{abstract}

Keywords: composition; sugar cane spirit; aging; woods.

\section{Introdução}

A produção de aguardente de cana e de cachaça no Brasil atinge 1,5 bilhões de litros anuais, representando $87 \%$ da produção nacional de bebidas alcoólicas destiladas. O consumo médio per capita do brasileiro é de 9,4 L/ano. O setor emprega cerca de 450 mil trabalhadores e movimenta internamente US\$1,0 bilhão por ano.
A aguardente de cana possui uma graduação alcoólica de 38 a $54 \%$ em volume, a $20^{\circ} \mathrm{C}$. É obtida de destilado alcoólico simples de cana-de-açúcar (Saccharum officinarum L.) ou pela destilação do mosto fermentado de cana-de-açúcar. Destilado alcoólico simples de cana-de-açúcar é o produto obtido pelo processo de destilação simples ou por destilo-retificação parcial

Recebido para publicação em 4/7/2008

Aceito para publicação em 16/5/2009 (003649)

Departamento de Agroindústria, Alimentos e Nutrição; Escola Superior de Agricultura "Luiz de Queiroz", Universidade de São Paulo - USP, Av. Pádua Dias, 11, CP 9,

CEP 13418-900, Piracicaba -SP, São Paulo,Brasil, E-mail: aralcard@esalq.usp.br

${ }^{*}$ A quem a correspondência deve ser enviada 
seletiva de mosto fermentado do caldo de cana-de-açúcar, com graduação alcoólica superior a $54 \%$ em volume e inferior a $70 \%$ em volume a $20^{\circ} \mathrm{C}$ (BRASIL, 2005a).

Cachaça é a denominação típica e exclusiva da aguardente de cana produzida no Brasil, com graduação alcoólica de 38 a $54 \%$ (v/v) a $20^{\circ} \mathrm{C}$, obtida pela destilação do mosto fermentado do caldo de cana-de-açúcar e com características sensoriais peculiares (BRASIL, 2005a).

A aguardente de cana envelhecida refere-se à bebida que contiver, no mínimo, 50\% de aguardente de cana envelhecida em recipiente de madeira apropriado, com capacidade máxima de $700 \mathrm{~L}$, por um período não inferior a um ano. Aguardente de cana premium é o destilado 100\% envelhecido em recipiente de madeira apropriado, com capacidade máxima de $700 \mathrm{~L}$, por um período mínimo de um ano. Aguardente de cana extra-premium é aquela 100\% envelhecida em recipiente de madeira apropriado, com capacidade máxima de $700 \mathrm{~L}$, por um período mínimo de três anos (BRASIL, 2005a).

$\mathrm{O}$ aperfeiçoamento tecnológico e o controle de qualidade do processo de produção da aguardente de cana só são possíveis mediante o conhecimento da composição química e da qualidade sensorial da bebida.

A mudança do aroma e do sabor da bebida maturada deve-se a alterações na composição e na concentração dos seus compostos, as quais são causadas por extração dos compostos da madeira; quebra de suas macromoléculas e extração dos seus produtos; reações entre os compostos do destilado e da madeira; reação entre os próprios extrativos da madeira; reação entre os próprios componentes do destilado; e evaporação de compostos voláteis (MOSEDALE; PUECH, 1998). Em tonéis de carvalho de $200 \mathrm{~L}$, as principais mudanças nas propriedades sensoriais da cachaça ocorreram nos primeiros 21 meses de envelhecimento (FARIA et al., 2003a).

Durante a maturação de bebidas destiladas, normalmente ocorre uma diminuição do $\mathrm{pH}$ e das concentrações de cobre, de álcool metílico e de álcool etílico, enquanto se observam aumentos da acidez, da cor e das concentrações de ésteres, aldeídos, furfural, álcoois superiores, coeficiente de congêneres e compostos fenólicos (PARAZZI et al., 2008; MIRANDA et al., 2008).

O envelhecimento da aguardente em tonéis de madeira promove diminuição significativa do sabor alcoólico e da agressividade da bebida, com simultâneo aumento da doçura e do sabor de madeira, proporcionando uma efetiva melhora sensorial do produto (CARDELLO; FARIA, 1999). É uma etapa indispensável, quando se deseja agregar qualidade e, consequentemente, valor a uma bebida destilada. No Brasil, infelizmente, o envelhecimento da aguardente não é prática comum, devido ao tempo requerido pelo processo e aos custos introduzidos pelo armazenamento da bebida em tonéis por alguns anos.

O carvalho é a madeira utilizada mundialmente para a confecção de tonéis para envelhecimento de bebidas destiladas, pois transfere compostos de aroma e sabor que tornam a bebida agradável ao paladar. Porém, dentre a ampla gama de espécies florestais nacionais, algumas delas já foram estudadas quanto à possibilidade de substituir o carvalho na construção de tonéis para envelhecimento de aguardente e de cachaça. Faria et al. (2003a) observaram que as cachaças envelhecidas nas madeiras amendoim, pereiro, jatobá, bálsamo e pau-d'arco mostraram características sensoriais favoráveis à qualidade da bebida.

Delgado, Marquese Almeida (1996) observaram queas madeiras ipê-roxo, amendoim, cabreúva, pereira e araruva propiciaram cor, aroma e sabor característicos a aguardentes envelhecidas, tendo sido consideradas apropriadas para o acondicionamento da bebida com a finalidade de envelhecimento.

O objetivo deste trabalho foi determinar aspectos da composição química e aceitação sensorial da aguardente de cana-de-açúcar envelhecida por 3 anos em tonéis de diferentes madeiras (amendoim, araruva, cabreúva, carvalho, cerejeira, grápia, jequitibá, ipê-roxo e pereira).

\section{Material e métodos}

A aguardente de cana-de-açúcar foi produzida em junho de 2005 na Destilaria Piloto do Departamento de Agroindústria, Alimentos e Nutrição da Escola Superior de Agricultura "Luiz de Queiroz" da Universidade de São Paulo. O mosto foi preparado a partir de canas da variedade SP 83-2847, de quarto corte, cultivadas nas dependências da Escola Superior de Agricultura "Luiz de Queiroz". O caldo foi extraído em moenda, submetido a tratamento térmico $\left(105^{\circ} \mathrm{C}\right)$, para eliminação de microrganismos contaminantes, e deixado em decantação por 2 horas para precipitação dos coloides. A fermentação foi realizada em dornas de $4 \mathrm{~m}^{3}$, utilizando a levedura Saccharomyces cerevisiae, cepa Y-904. O processo de fermentação foi em batelada alimentada com reciclo do fermento por decantação. Entre cada ciclo de fermentação, o fermento foi submetido a tratamento com ácido sulfúrico $(\mathrm{pH} 2,5$ por 2 horas, com agitação). O vinho foi destilado em coluna de destilação desenvolvida pela ESALQ/USP, com separação contínua das frações "cabeça" e "cauda" do destilado. Foram necessárias 12 bateladas de destilação para a produção do volume necessário de destilado alcoólico simples para envelhecimento (aproximadamente 9000 L). Durante o período demandado para a produção do volume total de destilado (28 dias), seus volumes parciais foram sendo armazenados em um tonel de madeira (amendoim) de $16 \mathrm{~m}^{3}$. O volume total de destilado foi então homogeneizado e distribuído em tonéis de diferentes madeiras: amendoim (Pterogyne nitens), araruva (Centrolobium tomentosum), cabreúva (Mycrocarpus frondosus), carvalho europeu (Quercus sp.), cerejeira (Amburana cearensis), grápia (Apuleia leiocarpa), ipê-roxo (Tabebuia heptaphylla), jequitibá (Cariniana estrellensis) e pereira (Platycyamus regnelli). Estes tonéis foram construídos na forma de tronco de cone: diâmetro interno da base de $66 \mathrm{~cm}$, altura útil de $86 \mathrm{~cm}$ e diâmetro interno da tampa de $54 \mathrm{~cm}$. Estas dimensões resultam em um volume médio dos tonéis de $245 \mathrm{~L}$, uma área interna de contato com a aguardente de $196 \mathrm{dm}^{2}$ (excluindo a tampa) e, consequentemente, uma relação volume/área de, aproximadamente, 1,25 L.dm ${ }^{-2}$. Estas dimensões, bem como estes parâmetros, se assemelham aos dos tonéis usualmente utilizados para o envelhecimento de whisky e cognac. Previamente ao experimento, os tonéis foram 
lavados com vapor de água, com água quente e com água fria, enchidos com aguardente e assim mantidos por 24 meses. Os tonéis não foram submetidos a nenhum processo de queima interna. Em seguida, os tonéis foram esvaziados e lavados com água fria, estando, assim, adequados para o envelhecimento da bebida. O destilado alcoólico simples (61\% de álcool em volume) foi envelhecido nos tonéis das diferentes madeiras por 3 anos, em adega, sob temperatura ambiente $\left(22 \pm 5^{\circ} \mathrm{C}\right) \mathrm{e}$ umidade relativa de $55 \pm 10^{\circ} \mathrm{C}$ e protegido de vibrações. Como tratamento testemunha, uma amostra do destilado alcoólico simples foi armazenada em recipiente de vidro durante o período de envelhecimento das aguardentes.

A testemunha e as aguardentes envelhecidas, devidamente diluídas com água potável, foram submetidas às análises de grau alcoólico, acidez volátil (em ácido acético), furfural, aldeídos, ésteres, álcoois superiores (n-propílico, isobutílico e isoamílico), álcool metílico, cobre, compostos fenólicos totais e cor (BRASIL, 2005b).

As análises cromatográficas de aldeídos (em aldeído acético), ésteres (em acetato de etila), álcoois superiores e álcool metílico foram efetuadas utilizando um cromatógrafo gasoso CG-037, equipado com uma coluna empacotada PAAC 3334-CG e um detector de ionização de chama (FID). Como gás de arraste, utilizou-se $\mathrm{H}_{2}$, com vazão de $30 \mathrm{~mL} /$ minuto. A temperatura do injetor foi programada para $170{ }^{\circ} \mathrm{C}$. A programação da temperatura da coluna foi isotérmica a $94^{\circ} \mathrm{C}$. A temperatura do detector foi programada para $225^{\circ} \mathrm{C}$ (BOZA, 1996). Foram efetuadas três injeções, de $3 \mu \mathrm{L}$ cada, para cada amostra. Utilizou-se padrão externo para a determinação dos tempos de retenção e da concentração dos componentes (Figura 1 e Tabela 1).

A determinação da intensidade de cor das aguardentes envelhecidas foi realizada mediante leitura de transmitância a $420 \mathrm{~nm}$. A concentração de compostos fenólicos totais foi determinada espectrofotometricamente a $700 \mathrm{~nm}$, após reação com o reagente de Folin-Ciocalteau (AMERINE; OUGH, 1980). Ácido gálico foi utilizado como padrão para a construção da curva de calibração.

As aguardentes envelhecidas nas diferentes madeiras foram avaliadas sensorialmente, mediante análise de aroma e sabor, por uma equipe de 30 provadores não treinados, sendo utilizadas escalas hedônicas de 9 pontos, conforme procedimento de

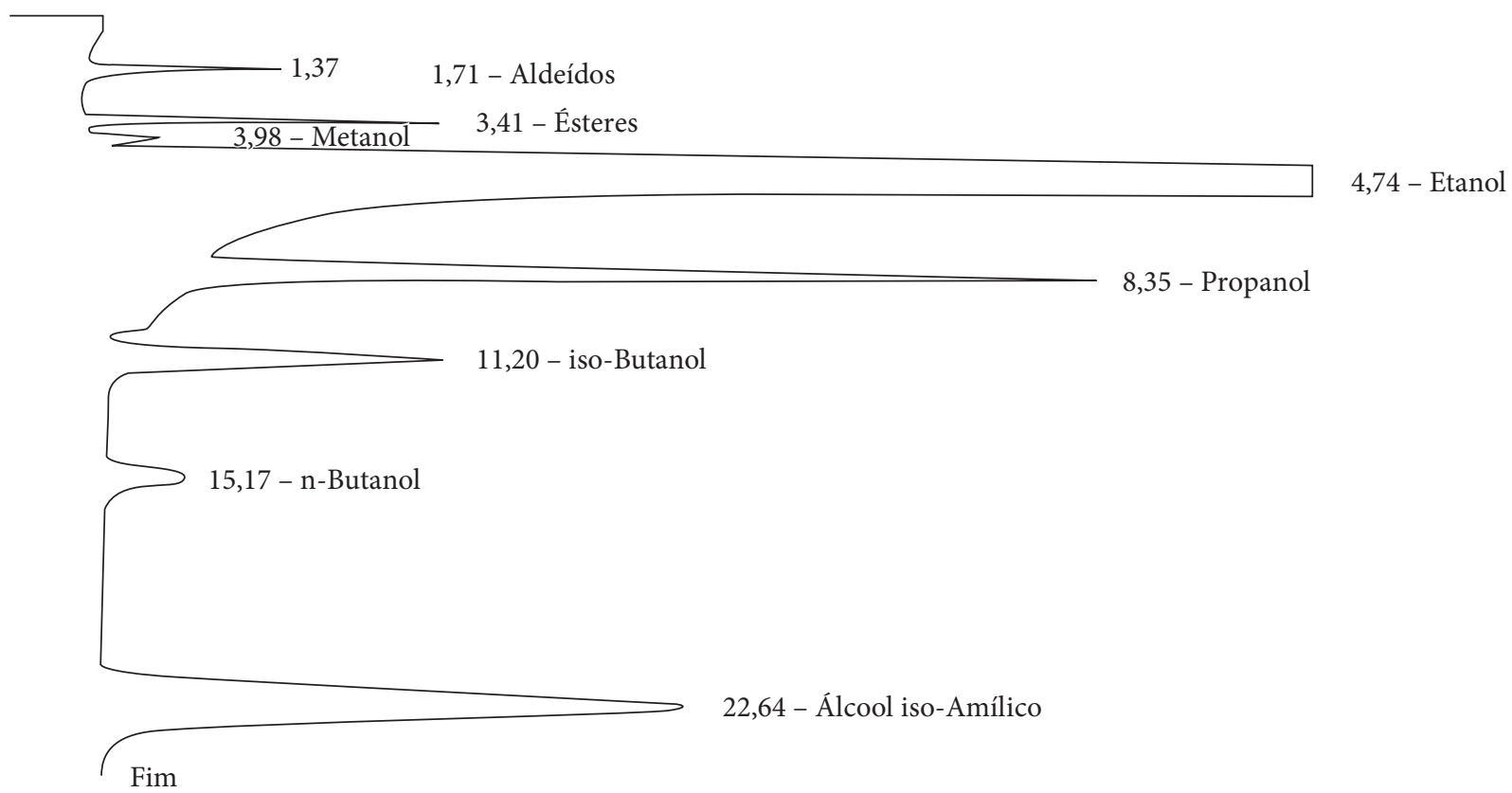

Figura 1. Cromatograma do padrão externo com a identificação do pico referente a cada composto analisado.

Tabela 1. Dados de calibração do analisador do cromatógrafo.

\begin{tabular}{lcccc}
\hline Componentes & $\begin{array}{c}\text { Tempo de retenção } \\
\text { (minutos) }\end{array}$ & $\begin{array}{c}\text { Concentração }(\mathrm{C}) \\
\left(\mathrm{mg} .100 \mathrm{~mL}^{-1}\right)\end{array}$ & $\begin{array}{c}\text { Área do pico } \\
(\mathrm{A})\end{array}$ & $\begin{array}{c}\text { Relação } \\
\text { C/A }\end{array}$ \\
\hline Aldeído acético & 1,71 & 7,88 & 3669 & 0,0021477 \\
Acetato de etila & 3,41 & 8,97 & 5863 & 0,0015299 \\
Metanol & 3,98 & 3,96 & 2140 & 0,0018505 \\
Propanol & 8,35 & 28,12 & 35940 & 0,0007824 \\
iso-Butanol & 11,2 & 12,03 & 17047 & 0,0007056 \\
Álcool iso-Amílico & 22,64 & 40,65 & 58292 & 0,0006973 \\
\hline
\end{tabular}


apresentação das amostras descrito por Macfie e Bratchell (1989).

O delineamento estatístico utilizado foi inteiramente casualizado. Os tratamentos referiram-se às madeiras dos tonéis de envelhecimento. $\mathrm{O}$ experimento contou com quatro repetições por tratamento, referentes aos 4 tonéis de cada madeira estudada. Com o auxílio do programa estatístico SAS (SAS, 1996), foram aplicados análise de variância (ANOVA) e teste de médias de Tukey a 5\% de significância (PIMENTEL-GOMES; GARCIA, 2002).

\section{Resultados e discussão}

A perda de volume do destilado durante o período de envelhecimento variou entre 16 e $28 \%$, em função da espécie de madeira utilizada nos tonéis. Observou-se que as madeiras que apresentam menor densidade foram aquelas em que a aguardente sob envelhecimento sofreu maior redução de volume. As aguardentes envelhecidas nos tonéis das madeiras cerejeira $\left(\mathrm{d}=0,60 \mathrm{~g} \cdot \mathrm{cm}^{-3}\right)$, araruva $\left(\mathrm{d}=0,75 \mathrm{~g} \cdot \mathrm{cm}^{-3}\right)$, amendoim $\left(\mathrm{d}=0,77 \mathrm{~g} \cdot \mathrm{cm}^{-3}\right)$ e jequitibá $\left(\mathrm{d}=0,78 \mathrm{~g} \cdot \mathrm{cm}^{-3}\right)$ apresentaram reduções médias de volume de 28, 25, 23 e 24\%, respectivamente. As aguardentes envelhecidas nos tonéis das madeiras pereira $\left(\mathrm{d}=0,81 \mathrm{~g} \cdot \mathrm{cm}^{-3}\right)$, grápia $\left(\mathrm{d}=0,83 \mathrm{~g} \cdot \mathrm{cm}^{-3}\right)$ e cabreúva $\left(\mathrm{d}=0,91 \mathrm{~g} \cdot \mathrm{cm}^{-3}\right)$ apresentaram reduções médias de volume de 22,22 e $20 \%$, respectivamente. As aguardentes envelhecidas nos tonéis das madeiras ipê-roxo $\left(\mathrm{d}=0,99 \mathrm{~g} \cdot \mathrm{cm}^{-3}\right)$ e carvalho $\left(\mathrm{d}=1,08 \mathrm{~g} . \mathrm{cm}^{-3}\right)$ apresentaram reduções médias de volume de 18 e $16 \%$, respectivamente.

Independentemente da madeira com que o tonel foi construído, a aguardente envelhecida apresentou coloração mais escura e maior concentração de acidez volátil, de furfural, de ésteres, de álcoois superiores, de congêneres e de compostos fenólicos totais que o destilado alcoólico simples. Por outro lado, a aguardente envelhecida apresentou menor concentração de aldeídos, de metanol e de cobre que o destilado alcoólico simples (Tabela 2).

Os resultados desta pesquisa concordam com os obtidos por Parazzi et al. (2008), os quais estudaram as principais alterações na composição química da aguardente de cana-de-açúcar envelhecida por 36 meses em tonéis de carvalho. Com o decorrer do período de envelhecimento observou-se aumento da acidez da bebida e das concentrações de ésteres, álcool isoamílico e compostos fenólicos totais.

Miranda et al. (2008) também observaram maiores concentrações de acidez volátil, ésteres, furfural, álcoois superiores, congêneres, extrato seco e tanino em aguardentes envelhecidas por 390 dias em tonéis de carvalho de $20 \mathrm{~L}$. Os autores observaram também ligeiro declínio no teor de cobre das aguardentes envelhecidas.

As aguardentes envelhecidas nos tonéis de araruva e jequitibá apresentaram maior acidez volátil que as envelhecidas nos tonéis de amendoim, carvalho e cerejeira, as quais, por sua vez, apresentaram-se mais ácidas que as envelhecidas nos tonéis de cabreúva, grápia, ipê-roxo e pereira.

O aumento da acidez volátil da aguardente envelhecida se deve à reação de oxidação do etanol, a qual contribui para a formação de acetaldeído, o qual, por sua vez, conduz à formação de ácido acético (REAZIN, 1981; LITCHEV, 1989). Além disso, alguns compostos oriundos da madeira, tais como ácidos orgânicos não voláteis, componentes secundários, taninos e compostos fenólicos, favorecem o aumento da acidez da aguardente em envelhecimento. A legislação mantém elevado o limite máximo de acidez volátil, visando proteger a aguardente envelhecida, cuja acidez sempre aumenta com o decorrer do período de envelhecimento. Desse modo, uma aguardente de baixa acidez inicial pode revelar seu grau de maturação pelo aumento da acidez volátil. Isso, todavia, não desqualifica o produto no aspecto sensorial pelo conjunto agradável que forma com outros componentes.

A aguardente envelhecida nos tonéis de ipê-roxo foi a que apresentou maior concentração de furfural. As aguardentes envelhecidas nos tonéis de amendoim, araruva, cabreúva, carvalho, cerejeira, jequitibá e pereira apresentaram concentração de furfural similar. A aguardente envelhecida nos tonéis de grápia foi a que apresentou menor concentração de furfural.

Tabela 2. Aspectos da composição química da aguardente envelhecida nos tonéis das diferentes madeiras.

\begin{tabular}{|c|c|c|c|c|c|c|c|c|c|c|c|}
\hline & Etanol $^{1}$ & $\begin{array}{l}\text { Acidez } \\
\text { Volátil }^{2}\end{array}$ & Furfural $^{2}$ & Aldeídos ${ }^{2}$ & Ésteres $^{2}$ & $\begin{array}{c}\text { Álcoois } \\
\text { superiores }\end{array}$ & $\begin{array}{l}\text { Coeficiente } \\
\text { congêneres }^{2}\end{array}$ & Metanol $^{2}$ & Cobre $^{3}$ & $\begin{array}{c}\text { Fenólicos } \\
\text { totais }^{4}\end{array}$ & Cor $^{5}$ \\
\hline Testemunha & $41,03^{\mathrm{a}}$ & $56,74^{\mathrm{a}}$ & $0,12^{\mathrm{a}}$ & $12,98^{\mathrm{a}}$ & $21,01^{\mathrm{a}}$ & $121,34^{\mathrm{a}}$ & $212,19^{\mathrm{a}}$ & $6,13^{a}$ & $0,32^{\mathrm{a}}$ & $0,03^{\mathrm{a}}$ & $100,0^{\mathrm{a}}$ \\
\hline Amendoim $^{\mathrm{a}}$ & $40,64^{a}$ & $108,76^{c}$ & $0,26^{c}$ & $8,62^{c}$ & $36,40^{\mathrm{d}}$ & $144,77^{\mathrm{b}}$ & $298,81^{\mathrm{b}}$ & $3,89^{\mathrm{b}}$ & $0,28^{\mathrm{b}}$ & $1,94^{\mathrm{b}}$ & $95,0^{\mathrm{b}}$ \\
\hline Cabreúva & $40,36^{\mathrm{a}}$ & $94,55^{\mathrm{b}}$ & $0,33^{c}$ & $7,67^{c}$ & $27,12^{\mathrm{c}}$ & $168,40^{c}$ & $298,07^{\mathrm{b}}$ & $3,43^{\mathrm{b}}$ & $0,19^{c}$ & $6,51^{\mathrm{c}}$ & $62,5^{c}$ \\
\hline Carvalho $^{c}$ & $40,91^{\mathrm{a}}$ & $104,94^{\mathrm{c}}$ & $0,29^{c}$ & $9,76^{c}$ & $30,45^{\mathrm{c}}$ & $195,74^{\mathrm{d}}$ & $341,18^{\mathrm{d}}$ & $4,08^{\mathrm{b}}$ & $0,14^{\mathrm{c}}$ & $12,44^{\mathrm{d}}$ & $38,5^{\mathrm{d}}$ \\
\hline Jequitibáa $^{a}$ & $41,23^{\mathrm{a}}$ & $124,18^{\mathrm{d}}$ & $0,32^{c}$ & $7,57^{\mathrm{c}}$ & $32,59^{c}$ & $166,5^{c}$ & $331,23^{\mathrm{d}}$ & $3,39^{\mathrm{b}}$ & $0,27^{\mathrm{b}}$ & $1,72^{\mathrm{b}}$ & $94,7^{\mathrm{b}}$ \\
\hline Ipê roxo ${ }^{c}$ & $41,68^{\mathrm{a}}$ & $93,84^{\mathrm{b}}$ & $0,46^{\mathrm{d}}$ & $7,91^{\mathrm{c}}$ & $23,07^{\mathrm{b}}$ & $176,81^{\mathrm{d}}$ & $302,09^{\mathrm{b}}$ & $3,46^{\mathrm{b}}$ & $0,07^{\mathrm{d}}$ & $40,61^{\mathrm{f}}$ & $14,7^{\mathrm{e}}$ \\
\hline Pereira $^{\mathrm{b}}$ & $40,69^{a}$ & $92,37^{\mathrm{b}}$ & $0,25^{c}$ & $8,04^{\mathrm{c}}$ & $22,98^{\mathrm{b}}$ & $188,04^{\mathrm{d}}$ & $311,68^{c}$ & $3,60^{\mathrm{b}}$ & $0,18^{c}$ & $5,30^{c}$ & $58,5^{\mathrm{c}}$ \\
\hline Legislação $^{6}$ & $38-54$ & $\leq 150$ & $\leq 5$ & $\leq 30$ & $\leq 200$ & $\leq 360$ & $200-650$ & $\leq 20$ & $\leq 5$ & presença & - \\
\hline
\end{tabular}

${ }^{1} \% \mathrm{v} / \mathrm{v} 20{ }^{\circ} \mathrm{C} ;{ }^{2} \mathrm{mg} .100 \mathrm{~mL}^{-1}$ álcool anidro; ${ }^{3} \mathrm{mg} \cdot \mathrm{L}^{-1} ;{ }^{4} \mathrm{mg} .100 \mathrm{~mL}{ }^{-1}$ ac. gálico; ${ }^{5}$ Transmitância a $\lambda=420 \mathrm{~nm} ;{ }^{6} \mathrm{IN} 13$ do Brasil (2005a); Mesma letra na mesma coluna significa que não existe diferença estatística a $5 \%$ de significância pelo teste de Tukey. 
O aumento do teor de furfural da aguardente envelhecida se deve à degradação de pentoses da madeira do tonel, conforme citado por Egorov e Rodopulo (1994).

As aguardentes envelhecidas nos tonéis das diferentes madeiras apresentaram a mesma concentração de aldeídos, com exceção da aguardente envelhecida nos tonéis de grápia, a qual apresentou concentração ligeiramente maior de aldeídos.

Os equilíbrios entre acetal e acetaldeído é particularmente importante para o aroma de bebidas destiladas, pois aldeídos frequentemente têm odor desagradável e pungente, enquanto os acetais são agradáveis e frutados (PIGGOTT; CONNER, 2003).

A aguardente envelhecida nos tonéis de grápia foi a que apresentou maior concentração de ésteres. As aguardentes envelhecidas nos tonéis de amendoim e araruva apresentaram maior concentração de ésteres que as envelhecidas nos tonéis de cabreúva, carvalho, cerejeira e jequitibá. As aguardentes envelhecidas nos tonéis de ipê-roxo e pereira foram as que apresentaram menor concentração de ésteres.

O aumento da concentração de ésteres pelo envelhecimento da aguardente é, principalmente, devido às reações de esterificação entre os álcoois e os ácidos da bebida. Os ésteres são produzidos durante a fermentação pelas leveduras e também durante o envelhecimento pela esterificação de ácidos graxos com etanol, sendo o acetato de etila o componente majoritário deste grupo (FARIA et al., 2003b) e responsável pelo odor agradável das bebidas envelhecidas (LITCHEV, 1989).

A aguardente envelhecida nos tonéis de grápia foi a que apresentou maior concentração de álcoois superiores. As aguardentes envelhecidas nos tonéis de carvalho, ipê-roxo e pereira apresentaram maior concentração de álcoois superiores que as envelhecidas nos tonéis de cabreúva, cerejeira e jequitibá. As aguardentes envelhecidas nos tonéis de amendoim e araruva foram as que apresentaram menor concentração de álcoois superiores.

O coeficiente de congêneres (componentes voláteis "não álcool") é a soma de acidez volátil, aldeídos, ésteres, álcoois superiores e furfural. Com exceção dos aldeídos, estes componentes separadamente tiveram suas concentrações consideravelmente aumentadas com o envelhecimento, resultando, portanto, em aumento do coeficiente de congêneres das aguardentes envelhecidas.

A aguardente envelhecida nos tonéis de grápia foi a que apresentou maior coeficiente de congêneres. As aguardentes envelhecidas nos tonéis de carvalho e jequitibá apresentaram maior coeficiente de congêneres que as envelhecidas nos tonéis de araruva, cerejeira e pereira. As aguardentes envelhecidas nos tonéis de amendoim, cabreúva e ipê-roxo foram as que apresentaram menor coeficiente de congêneres.

As aguardentes envelhecidas nos tonéis das diferentes madeiras apresentaram a mesma concentração de metanol. Álcool metílico em destilados tem origem na hidrólise de matérias pécticas. Como o teor de matérias pécticas em cana-de-açúcar é baixo, o teor de álcool metílico em seus destilados também é sempre baixo.
Mesmo apesar da relativa baixa concentração de cobre no destilado alcoólico simples, observou-se diminuição do teor deste elemento nas aguardentes envelhecidas. Isto deve ter ocorrido devido à absorção ou à adsorção do elemento pela madeira dos tonéis. Ainda, segundo Singleton (1995), compostos fenólicos podem reagir com o cobre do destilado, favorecendo o escurecimento da bebida. Neste trabalho, as aguardentes que apresentaram maiores concentrações de compostos fenólicos foram também aquelas que apresentaram menor concentração de cobre.

As aguardentes envelhecidas nos tonéis de cerejeira, grápia e ipê-roxo apresentaram menor concentração de cobre que as envelhecidas nos tonéis de cabreúva, carvalho e pereira, as quais, por sua vez, apresentaram menor concentração de cobre que as envelhecidas nos tonéis de amendoim, araruva e jequitibá.

A concentração de compostos fenólicos e a intensidade de cor foram as análises que apresentaram os resultados mais discrepantes entre as aguardentes envelhecidas nas diferentes madeiras. Apesar de não ter sido observada uma correlação diretamente proporcional, observou-se influência dos compostos fenólicos no escurecimento das aguardentes, evidenciada pela análise da intensidade de cor (\%transmitância) da bebida após o envelhecimento.

Este trabalho não analisou os diferentes compostos fenólicos das aguardentes. Tal informação poderia contribuir com dados mais específicos da influência dos diferentes compostos fenólicos no sabor, no aroma e na cor das aguardentes.

As aguardentes envelhecidas nos tonéis de cerejeira e ipê-roxo foram as que apresentaram maior concentração de compostos fenólicos totais. A aguardente envelhecida nos tonéis de grápia apresentou maior concentração de compostos fenólicos totais que a envelhecida nos tonéis de carvalho, a qual, por sua vez, apresentou maior concentração de compostos fenólicos totais que as envelhecidas nos tonéis de cabreúva e pereira. As aguardentes envelhecidas nos tonéis de amendoim, araruva e jequitibá foram as que apresentaram menor concentração de compostos fenólicos totais.

Dias, Maia e Nelson (1998) caracterizaram alguns taninos e compostos fenólicos em aguardente de cana envelhecida por 6 meses em barris de $20 \mathrm{~L}$ de madeiras nativas nacionais (amburana, bálsamo, jequitibá, jatobá e ipê-roxo) e constataram que cada madeira introduziu predominantemente de um a três compostos fenólicos específicos na bebida, sendo ácidos elágico e vanílico no carvalho; ácido vanílico e sinapaldeído na amburana; vanilina e ácido elágico no bálsamo; ácido gálico no jequitibá; coniferaldeído no jatobá; e ácidos siríngico e vanílico e coniferaldeído no ipê-roxo. Os autores concluíram que as madeiras brasileiras testadas incorporaram à aguardente compostos fenólicos presentes em bebidas envelhecidas em barris de carvalho.

No envelhecimento de bebidas destiladas ocorre degradação da lignina da madeira do tonel pelo etanol, resultando em compostos aromáticos como vanilina, siringaldeído, coniferaldeído e sinapaldeído. Além da extração destes compostos pelo álcool etílico, ocorrem ainda alterações na lignina em decorrência de oxidações e etanólise, as quais 
determinam denominações como "vanila", "adocicado" e “amadeirado” no destilado (PIGGOTT; CONNER, 2003).

As aguardentes envelhecidas nos tonéis de cabreúva, carvalho, cerejeira, grápia, ipê-roxo e pereira tornaram-se amareladas devido à extração de compostos fenólicos da madeira e suas reações de oxidação, as quais, segundo Singleton (1995), são os maiores responsáveis pelo progressivo escurecimento ou intensificação da cor amarelo-alaranjado em bebidas envelhecidas em madeiras. As aguardentes envelhecidas nos tonéis de grápia e ipê-roxo apresentaram-se mais escuras que as envelhecidas nos tonéis de carvalho e cerejeira, as quais, por sua vez, apresentaram-se mais escuras que as envelhecidas nos tonéis de cabreúva e pereira. As aguardentes envelhecidas nos tonéis de amendoim, araruva e jequitibá praticamente mantiveram a transparência original do destilado alcoólico simples.

Segundo Mendes, Mori e Trugilho (2002), a aguardente sob envelhecimento em madeira torna-se amarelada devido à extração progressiva dos compostos fenólicos da madeira do tonel.

Embora a medida espectrofotométrica na região de 400 a $430 \mathrm{~nm}$ normalmente esteja relacionada com a concentração de compostos fenólicos em bebidas envelhecidas (REAZIN, 1981), não foi observada correlação direta entre a transmitância medida dos destilados a $420 \mathrm{~nm}$ e suas respectivas concentrações de compostos fenólicos. Este resultado era esperado devido às madeiras terem diferentes estruturas físicas e, consequentemente, diferentes taxas quantitativas e qualitativas de extração de seus compostos fenólicos (DIAS; MAIA; NELSON, 1998).

A análise estatística geral, considerando a composição físico-química global das aguardentes envelhecidas nos tonéis das diferentes madeiras, indicou similaridades entre as aguardentes envelhecidas nos tonéis de amendoim, araruva e jequitibá; entre as aguardentes envelhecidas nos tonéis de cabreúva e pereira; e entre as aguardentes envelhecidas nos tonéis de carvalho, cerejeira, grápia e ipê-roxo (Tabela 1).

Independentemente do tipo de madeira dos tonéis, todas as aguardentes envelhecidas apresentaram-se dentro dos padrões de qualidade estabelecidos pela Instrução Normativa $n^{\circ} 13$ de 30 de junho de 2005 (BRASIL, 2005a) (Tabela 1).

A aguardente envelhecida na madeira carvalho foi a que apresentou a melhor aceitação sensorial pelos provadores, tanto em aroma como em sabor. Dentre as madeiras nacionais, ipêroxo, amendoim, cabreúva, cerejeira e pereira foram aquelas que propiciaram as melhores qualidades sensoriais à aguardente (Tabela 3). A aguardente testemunha, isto é, aquela armazenada em recipiente de vidro, foi a que obteve dos provadores as notas mais baixas, tanto para o aroma como para o sabor.

Faria et al. (2003a) compararam cachaças envelhecidas por 6 meses em tonéis de $15 \mathrm{~L}$ de madeiras nacionais (amarelo, amendoim, bálsamo, jatobá, louro, pau-d'arco, pau-d'óleo e pereiro) e em carvalho, avaliando propriedades sensoriais, compostos fenólicos e intensidade de coloração. Os atributos sensoriais sugeriram que amendoim e pereiro, seguidos do jatobá, bálsamo e pau-d'arco são bons candidatos a substituir o carvalho na construção de tonéis para envelhecimento da
Tabela 3. Notas atribuídas pelos provadores na análise de aceitação sensorial das aguardentes envelhecidas.

\begin{tabular}{lcc}
\hline & Aroma & Sabor \\
\hline Testemunha & $5,1^{\mathrm{d}}$ & $5,5^{\mathrm{d}}$ \\
Amendoim & $7,4^{\mathrm{b}}$ & $7,2^{\mathrm{b}}$ \\
Araruva & $6,1^{\mathrm{c}}$ & $6,3^{\mathrm{c}}$ \\
Cabreúva & $7,0^{\mathrm{b}}$ & $7,0^{\mathrm{b}}$ \\
Carvalho & $8,4^{\mathrm{a}}$ & $8,6^{\mathrm{a}}$ \\
Cerejeira & $7,9^{\mathrm{ab}}$ & $7,1^{\mathrm{b}}$ \\
Grapia & $6,5^{\mathrm{c}}$ & $5,9^{\mathrm{c}}$ \\
Jequitibá & $6,5^{\mathrm{c}}$ & $6,0^{\mathrm{c}}$ \\
Ipê roxo & $7,7^{\mathrm{b}}$ & $7,5^{\mathrm{b}}$ \\
Pereira & $7,3^{\mathrm{b}}$ & $6,9^{\mathrm{b}}$ \\
\hline
\end{tabular}

Mesma letra na mesma coluna significa que não existe diferença estatística a $5 \%$ de significância pelo teste de Tukey.

cachaça. Os testes sensoriais não detectaram diferença na aceitabilidade das cachaças envelhecidas no carvalho e na madeira amendoim.

Delgado, Marques e Almeida (1996), analisando aguardentes envelhecidas em amendoim, jequitibá, ipê-roxo, araruva, cabreúva e pereira, observaram que as madeiras que propiciaram melhores características sensoriais de qualidade à aguardente em relação à cor, aroma e sabor foram, pela ordem, ipê-roxo, amendoim, cabreúva, pereira, araruva e jequitibá.

\section{Conclusões}

A aguardente envelhecida nos tonéis das diferentes madeiras manteve-se dentro de todos os padrões de qualidade estabelecidos pela legislação nacional em vigor.

As aguardentes envelhecidas, independentemente da madeira com que o tonel foi construído, apresentaram coloração mais escura e maior concentração de acidez volátil, de furfural, de ésteres, de álcoois superiores, de congêneres e de compostos fenólicos totais. Por outro lado, a aguardente envelhecida apresentou menor concentração de aldeídos, de metanol e de cobre.

A composição físico-química global das aguardentes envelhecidas nos tonéis das diferentes madeiras indicou similaridades entre elas, as quais poderiam ser assim agrupadas em relação à madeira dos tonéis em que foram envelhecidas: grupo 1 - amendoim, araruva e jequitibá; grupo 2 - cabreúva e pereira; grupo 3 - carvalho, cerejeira, grápia e ipê-roxo.

A aguardente envelhecida na madeira carvalho foi a que apresentou a melhor aceitação sensorial. Dentre as madeiras nacionais, ipê-roxo, amendoim, cabreúva, cerejeira e pereira foram aquelas que propiciaram as melhores qualidades sensoriais à aguardente.

\section{Referências bibliográficas}

AMERINE, M. A.; OUGH, C. S. Methods for analysis of musts and wines. New York: Wiley, 1980. 341 p.

BOZA, Y. E. A. G. Influência da condução da destilação sobre a composição e a qualidade sensorial da aguardente de cana. 
Piracicaba, 1996. 143 f. Dissertação (Mestrado) - Universidade de São Paulo - USP.

BRASIL. Ministério da Agricultura, Pecuária e Abastecimento. Instrução Normativa n. 13, de 29 de junho de 2005. Aprova o regulamento técnico para fixação dos padrões de identidade e qualidade para aguardente de cana e para cachaça. Diário Oficial da União, Poder Executivo, Brasília, DF, 30 jun. 2005a.

BRASIL. MINISTÉRIO DA AGRICULTURA, PECUÁRIA E ABASTECIMENTO. Instrução Normativa n. 24, de 08 de setembro de 2005. Aprova o manual operacional de bebidas e vinagres. Diário Oficial da União, Poder Executivo, Brasília, DF, 09 de set. 2005b.

CARDELLO, H. M. A. B.; FARIA, J. B. Análise tempo-intensidade de características sensoriais de cachaça de cana durante o envelhecimento em tonel de carvalho (Quercus sp). Boletim da Sociedade Brasileira de Ciência e Tecnologia de Alimentos, v. 33, n. 1, p. 27-34, 1999.

DELGADO, A. A.; MARQUES, T. A.; ALMEIDA, C. L. F. Madeiras nacionais para envelhecimento natural de aguardente. Álcool \& Açúcar, v. 16, n. 83, p. 22-27, 1996.

DIAS, S.; MAIA, A.; NELSON, D. Effect of different types of woods on the composition of aged sugar cane spirits. Ciência e Tecnologia de Alimentos, v. 18, n. 3, p. 331-336, 1998.

EGOROV, I. A.; RODOPULO, A. K. Investigation of aroma-forming substances in cognac spirits in their aging process. Applied Biochemistry and Microbiology, v. 30, n. 4-5, p. 539-542, 1994.

FARIA, J. B. et al. Evaluation of Brazilian woods as an alternative to oak for cachaças aging. European Food Research and Technology, v. 218 , n. 1, p. 83-87, 2003a.

FARIA, J. B. et al. Cachaça, pisco e tequila. In: LEA, A. G. H.; PIGGOTT, J. R. (Eds.). Fermented beverage production. 2 ed. New York: Klumer Academic, 2003b. cap. 15, p. 335-363.

LITCHEV, V. Influence of oxidation process on the development of the taste and flavor of wine distilates. American Journal of Enology and Viticulture, v. 40, n. 1, p. 31-35, 1989.
MACFIE, H. J.; BRATCHELL, N. Designs to balance the effect of order of presentation and first order carry-over effects in hall tests. Journal of Sensory Studies, v. 4, n. 2, p. 129-148, 1989.

MENDES, L. M.; MORI, F. A.; TRUGILHO, P. F. Potencial da madeira de agregar valor à cachaça de almabique. Informe Agropecuário, v. 23, n. 213, p. 52-58, 2002.

MIRANDA, M. B. et al. Perfil físico-químico de aguardente durante envelhecimento em tonéis de carvalho. Ciência e Tecnologia de Alimentos, v. 28, n. 2, p. 313-319, 2008. (no prelo)

MOSEDALE, J. R.; PUECH, J. L. Wood maturation of distilled beverages. Trends in Food Science \& Technology, v. 9, n. 3, p. 95-101, 1998.

PARAZZI, C. et al. Avaliação e caracterização dos principais compostos químicos da aguardente de cana-de-açúcar envelhecida em tonéis de carvalho (Quercus sp.). Ciência e Tecnologia de Alimentos, v. 28 , n. 1, p. 193-199, 2008.

PIGGOTT, J. R.; CONNER, J. M. Whiskies. In: LEA, A. G. H.; PIGGOTT, J. R. (Eds.). Fermented beverage production. 2 ed. New York: Klumer Academic, 2003. cap. 11, p. 239-262.

PIMENTEL-GOMES, F.; GARCIA, C. H. Estatística aplicada a experimentos agronômicos e florestais: exposição com exemplos e orientações para uso de aplicativos. Piracicaba: FEALQ, 2002. $309 \mathrm{p}$.

REAZIN, G. H. Chemical mechanisms in whiskey maturation. American Journal of Enology and Viticulture, v. 32, n. 4, p. 283-289, 1981.

STATISTICAL ANALYSIS SYSTEM - SAS. Sas/Qc software: usage and reference. 2 ed. Cary, 1996. (2 v)

SINGLETON, V. L. Maturation of wines and spirits: comparison, facts and hypotheses. American Journal of Enology and Viticulture, v. 46, n. 1, p. $98-115,1995$. 